\title{
IDENTIFICAÇÃO DA MULTA DA POBREZA NOS ESTRATOS RURAL URBANO E CAPITAL DO ESTADO DE SERGIPE: UM ESTUDO APLICANDO AS IDEIAS DE PRAHALAD.
}

\author{
Identifying Poverty Fine in Rural Urban and Capital Classifications at Sergipe State: Case \\ Study Using Prahalad Ideas.
}

\author{
Tácito Augusto Farias ${ }^{1}$ \\ Wagner Nóbrega ${ }^{2}$ \\ Luiz Eduardo Nascimento Figueiredo ${ }^{3}$ \\ José Henrique Santos Rodrigues ${ }^{4}$
}

\begin{abstract}
Resumo: O presente artigo tem como objetivo observar a existência e as formas de atuação da multa da pobreza nos estratos Capital, Rural e Urbano do estado de Sergipe, a partir dos dados da Pesquisa de Orçamento Familiar do IBGE para os anos de 2002-2003 e 2008-2009. Como meio de análise foram usados indicadores definidos por Prahalad (2005), comparando as despesas com alimentação e os diferentes grupos de despesas em geral. Para isso, foram usados os preços relativos como instrumentos. Os resultados obtidos indicam e confirmam a existência da multa da pobreza em todos os três estratos.

Palavras chave: Pobreza. Multa da pobreza. Despesas com alimentação. Despesas orçamentárias domiciliares.

Abstract: This paper purposes to observer existence and schedules of poverty fine on the classifications Capital, Rural and urban at Sergipe state, from IBGE'household budget research data in periods 2002 / 2003 and 2008 / 2009. Use knowledge from Prahalad. Results confirm existence of poverty fine in all classifications three.
\end{abstract}

Key-words : poverty, poverty fine, food expenses, household budgets.

Classificação JEL : A1.

\section{INTRODUÇÃO}

O conceito de "multa da pobreza" tem sua origem no livro "The Poor Pay More", de David Caplovitz (1963), um estudo sociológico, no qual o autor percebe que os gastos com alimentos, que as famílias de baixa renda de Nova York possuiam, eram superiores aos apresentados pelas famílias com nível de renda maior.

De acordo com Caplovitz (1963) as famílias consideradas pobres enfrentavam dificuldades relacionadas aos seus gastos com alimentação. No comparativo entre o volume de consumo dessas famílias e o seu respectivo custo em relaçãoas famílias ditas não pobres, foi observado que as primeiras se encontravam em desvantagem, muitas vezes pagando preços superiores pelo mesmo produto e quantidade, ou até mesmo, por uma quantidade menor e/ou de qualidade inferior.

Após o estudo pioneiro de David Caplovitz (1963), contribuíram com o conceito os autores Kunreuther (1973), C. K. Prahalad (2005), Hammond et al. (2007) e Mendoza (2011).

\footnotetext{
${ }^{1}$ Professor Efetivo do Departamento de Economia da Universidade Federal de Sergipe. Doutor em Economia USP

2 Professor Efetivo do Departamento de Economia da Universidade Federal de Sergipe.

${ }^{3}$ Mestrando em Economia PIMES/UFPE.

${ }^{4}$ Graduado em Economia pela Universidade Federal de Sergipe.
} 
A contribuição teórica de Kunreuther (1973) consistiu em apresentar um esquema explicativo de tomada de decisões dos compradores de comida na cidade de Nova York nos anos 1971, diante de diferentes tamanhos de pacotes de compras de mesmos itens. Empiricamente, o autor testou esse esquema, com dados para a cidade de New Haven, no verão de 1971.

Para construir suas hipóteses, Kunreuther (1973) distinguiu entre "efeito tamanho da loja" e "efeito tamanho do pacote de alimento". No primeiro, considerou itens de mesmo tamanho e qualidades padronizadas. Assim, o autor sugeriu que se o preço de um dado peso fixo, para qualquer tamanho de pacote, variar inversamente com o "tamanho da loja", as pessoas que compram em grandes estabelecimentos possuiriam custos inferiores a aqueles que comprassem lojas menores.

Enquanto que, o efeito "tamanho do pacote de alimento" se referia aos diferentes preços para os vários possíveis tamanhos de pacotes de um determinado produto de qualidade/marco padrão. Se o preço em relação ao peso variar inversamente com o tamanho do pacote, as pessoas pobres, que só podem comprar pacotes pequenos em razão de restrição orçamentaria acabarão pagando mais, pela mesma quantidade, do que se pudessem comprar embalagens maiores. (KUNREUTHER, 1973).

Para Prahalad (2005), a multa da pobreza é resultado, principalmente, dos monopólios locais e das dificuldades de acesso a outras oportunidades de compras. Portanto, a ideia geral do conceito de multa da pobreza é que as famílias pobres, para certos tipos de gastos, pagariam mais do que as famílias não pobres. Prahalad (2005) atribuiu a esses gastos o conceito de "gastos catastróficos", que recebem essa denominação quando o domicílio tem que reduzir as despesas com outros grupos básicos de gastos (como educação, por exemplo) por algum tempo para poder arcar com os esses tipos de gasto,

Em seu trabalho, usando os gastos com saúde como base, o autor estabeleceu uma análise da composição dos gastos dos domicílios em relação a itens de saúde e comparou com a composição dos gastos com outros grupos de despesas. Usando critérios de diferenciação de domicílios como condições de moradia, nível de escolaridade dos moradores e renda, o autor considerou o gasto com saúde como "catastrófico" pois outros gastos seriam prejudicados para conseguir se arcar com os custos de saúde.

Assim, o critério de definição da existência de multa da pobreza, para Prahalad (2005), seria quando houvesse variação positiva nas despesas com algum item de consumo e isso levasse a uma redução nos gastos catastróficos.

Hammond et al. (2007) contribuiram para o conceito de multa da pobreza, à medida que apontaram instrumentos de intervenção sobre a pobreza, através da caracterização da multa. Isto foi feito à medida que os autores perceberam que a parcela da população que está na base da pirâmide de renda no mundo, com renda familiar anual inferior a $\$ 3.000$ de dólares, era muito grande (estimada em 4 bilhões). Combinado a isto, os autores constataram que essa população estava caracterizada por se encontrar, em sua maioria, na zona rural, inseridas em mercados geralmente informais e desorganizadas. Sendo assim muito dependentes aos meios de subsistência, e expostos facilmente a exploração por parte de empregadores e intermediários. Observaram ainda, que os orçamentos dessa parte da população encontravam-se mais comprometidos com alimentação quanto menor fosse a renda. Finalmente, observaram também, que essas pessoas sofreram a multa da pobreza. Isso os levou a concluir que a 
entrada dessas pessoas no mercado formal e a oferta de serviços básicos às mesmas faria com que muitos negócios surgissem. Para tanto seria necessário retirarem as barreiras que inibem tal potencial, ou seja, as barreiras impostas pela multa da pobreza.

Para isso seria necessário suprir as necessidades da população pobre mundial. Sendo isso um passo essencial para o aumento do bem-estar, da produtividade e da capacidade dessas pessoas buscarem e alcançarem novos padrões de vida. Outro ponto importante, a eliminação da multa da pobreza aumentaria a renda das pessoas pobres, aumentando o poder de compra, e consequentemente sua participação na economia (HAMMOND et al, 2007).

Já Mendoza (2011), com uma versão mais atual e um tanto completa sobre o tema, diz que a participação da população pobre na economia de mercado tem se tornado mais difícil e custosa. Onde entender essas dificuldades e despesas pode auxiliar na busca pela explicação do porquê de os pobres serem marginalizados, e o que pode ser feito, na forma de politicas econômicas e/ou sociais, para tentar superar essa situação.

Mendonza (2011) sistematiza as diversas óticas do conceito de multa da pobreza, nos seguintes grupos:

- Qualidade inferior: visão relacionada aos produtos, quando os produtos que os pobres adquirem são de pior qualidade em relação àqueles adquiridos pelos não-pobres, a preços similares;

- Preço mais alto: visão relacionada aos preços, quando os pobres encontram produtos similares àqueles vendidos aos não-pobres, porém, a um preço mais alto;

- Falta de acesso: quando os preços são altos o suficiente para impedir as pessoas pobres de ter acesso a tais produtos;

- Falta de uso: quando, além dos altos preços ou da baixa qualidade, o consumidor abandona o mercado do bem ou serviço por algum outro fator que o impede;

- Catastrofismo: quando o conceito está relacionado ao de "gastos catastróficos" de Prahalad (2005).

Assim, segundo a visão de Mendonza (2011), a multa da pobreza pode então ser definida como as formas de exclusão e marginalização que as pessoas pobres enfrentam quando participam do contexto do sistema de mercado.

Para este trabalho, foi usado o modelo desenvolvido por Prahalad (2005), onde os gastos com alimentação são utilizados como possível exemplo de "gasto catastrófico", relacionando-os aos outros itens de despesas e calculando seus preços em relação aos preços da própria alimentação. A multa da pobreza, de acordo com essa abordagem, se configura de forma que quando a variação desses preços relativos, no comparado entre pobres e não pobres torne-se mais prejudicial para os domicílios pobres.

\section{DADOS}

Os dados usados neste artigo foram extraídos das tabelas de despesas da POF. A investigação então foi feita para o Estado de Sergipe e seus estratos Capital, Urbano sem capital e Rural, segundo a estratificação da 
Pesquisa de Orçamento Familiar (POF), realizada pelo IBGE, nas quais constam as informações sobre despesas com alimentação e de outros grupos.

As despesas com alimentação estão, muitas vezes, distribuídas em grupos, os quais não são exatamente os mesmos em cada ano. Por isso, as informações relativas aos grupos de alimentos foram extraídas seguindo-se uma tabela de conversão, que reordena os grupos da tabela "Caderneta de Despesa" da POF 2008-2009 conforme os grupos da mesma tabela da POF 2002-2003.

Quanto às informações monetárias (despesas, renda total domiciliar e renda domiciliar per capita), estas foram deflacionados pelo INPC - alimentos e bebidas, calculado e divulgado pelo Instituto Brasileiro de Geografia e Estatística, Sistema Nacional de Índices de Preços ao Consumidor (IBGE/SNIPC). A data-base utilizada para esta deflação foi janeiro de 2003, data essa utilizada para o deflacionamento pelo IBGE dos dados de diversas datas dentro da mesma tabela "Caderneta de Despesa" da POF 2002-2003.

Para o cálculo dos preços foi necessário proceder a um cálculo especifico, conforme o formato das informações em cada POF. Isto porque, o preço não foi perguntado nos questionários das POFs. Para calculá-lo na POF 2002-2003, dividiu-se o valor da despesa deflacionado anualizado por 12 e o resultado foi dividido pelo produto da quantidade (em kg) por 4. Para calculá-lo na POF 20082009, dividiu-se o valor da despesa anualizado e expandido pelo fator de expansão. O resultado foi dividido por 12 , cujo quociente, foi dividido pelo produto entre a quantidade adquirida (em kg) e 4.

Cabe notar que sendo preços pagos uma variável informada pelos entrevistados, a análise feita no artigo segue a ótica da demanda.

As informações de quantidades adquiridas em quilograma, por sua vez, são aquelas fornecidas na própria base de dados. As conversões das diversas unidades de medidas de alimentos para quilograma, portanto, são feitas pelo IBGE.

Observe-se que não se pôde trabalhar com informações para agregados de alimentos (grupos 99 da POF 2002-2003 e 90 da POF 2008-2009), porque 0 IBGE não procedeu à conversão das quantidades para quilograma, o que inviabilizou tanto a extração de informações de quantidades - dada nossa necessidade de padronização para comparação - quanto o cálculo dos preços para esses grupos de alimentos, que foi como visto acima baseado na informação da quantidade em quilograma.

A identificação de domicílios pobres e a consequente distinção entre esses e os não pobres foi baseada na combinação de um critério objetivo/quantitativo e um subjetivo/qualitativo. Como critério objetivo adotou-se a insuficiência calórica, entendendo-se essa como saldo calórico negativo entre a caloria estimada para a quantidade e tipo de alimentos adquiridos e as necessidades calóricas requeridas pelos moradores do domicílio, por suas características antropométricas e de atividade físicas. Os critérios para tanto foram destacados pela Food and Drug Administration (FDA). Como critério subjetivo considerou-se a insatisfação com a alimentação, em termos de quantidade adquirida e qualidade dos alimentos. Para isto, foram tomados como dados as declarações dos respondentes do domicílio, dizendo-se tanto insatisfeitos com as quantidades, quanto com a qualidade dos alimentos. Consequentemente, os domicílios considerados pobres são aqueles que, simultaneamente, indicaram insatisfação quanto ao tipo e quantidade de alimentos adquiridos e que apresentaram insuficiência calórica. Por associação, 
os domicílios não pobres são os que indicaram serem satisfeitos quanto à alimentação, e apresentaram suficiência calórica.

\section{METODOLOGIA}

Para este trabalho, utilizamos o indicador, para a multa da pobreza, desenvolvido por Prahalad (2005) com dados referentes aos preços pagos pelos domicílios pobres e não pobres dos três estratos do estado de Sergipe (Rural, Urbano, Capital) em relação aos grupos de despesas presentes nas POFs. Assim tratou-se a multa da pobreza em termos de o quanto a variação de preços pode ter contribuído para piorar o quadro de pobreza. O indicador para a multa da pobreza em Prahalad (2005) foi tratado em termos de variação, visto que foi identificada a pobreza para os pares de grupos de despesa cujo preço médio dividido pelo preço médio do conjunto de alimentos aumentou mais para os domicílios pobres do que para os não pobres.

Dessa maneira foram calculados os preços, relativos à alimentação, para todos os grupos de despesas analisados. A partir disso, foram calculadas as variações dos preços relativos no período em questão e selecionados aqueles grupos de despesas que apresentaram maior aumento dos preços relativos para os domicílios pobres e os que apresentaram menor redução dos preços também para esse mesmo grupo de domicílios. Ou seja, os grupos de despesas que tiveram variações de preços mais desfavoráveis aos domicílios pobres.

Feito isso, o próximo passo foi buscar dados de preços pagos pelos domicílios que realizaram gastos simultaneamente com alimentação e com algum dos itens previamente selecionados, e com base na taxa de variação desses dados, realizou-se as análises necessárias.

Como indício de multa da pobreza foi observada, em uma primeira etapa, a comparação entre as variações dos preços relativos para os pobres e para os não pobres, de forma que naqueles grupos de despesas onde os domicílios pobres apresentaram maior aumento ou menor redução de preços do que os não pobres, encontrou-se a indicação da multa.

E para confirmar essa situação, numa segunda etapa de análise, buscou-se incrementar a especificidade dos resultados ao analisar os domicílios que realizaram gastos simultaneamente com alimentação e o item de despesa especificado na primeira etapa de análise. Assim, mais uma vez foi calculado o preço relativo à alimentação desses, e realizada a mesma análise de variação entre esses preços, sabendo ou não se foi mais prejudicial aos domicílios pobres.

Depois de identificados os grupos de despesas com alimentos e de outras despesas relacionadas às do conjunto da alimentação para os quais os indicadores apontaram indícios de multa da pobreza, testamos a multa da pobreza. Para tanto, usou-se uma variável-teste para o indicador. Essa variável-teste é o avanço da proporção da despesa na renda dos domicílios pobres que a realizaram, relativamente ao avanço da mesma para os domicílios não-pobres.

Como a variável utilizada nesse trabalho pra indicar a multa da pobreza foram os preços relativos à alimentação, na realização do teste também foi preciso usar uma relação entre a participação da despesa do item na renda do domicílio e a participação da despesa com alimentação na renda do mesmo domicílio, ou seja: 


$$
\text { Relação }=\frac{\text { Desp.Item } / \text { Renda }}{\text { Desp.Alimentação } / \text { Renda }}
$$

E a partir disso, a variável-teste indicou a multa da pobreza nos grupos de despesa onde a variação dessa relação foi prejudicial para os domicílios pobres.

Vale apontar que, nesse item, chamou-se de variável-hipótese aquilo que foi usado como proxy da análise aqui proposta, ou seja, os resultados de multa segundo a variação nos preços relativos. Sendo assim, seguiu-se o mesmo sistema de 1 e 0 , ou seja, quando a análise baseada nessas variáveis indicou existência de multa da pobreza, atribuiu-se 1, e quando não, 0 .

\section{RESULTADOS}

\subsection{Visão Geral dos Quantitativos de Domicílios}

Primeiramente, antes de se observar os dados referentes à multa da pobreza, é necessários apresentar um panorama geral do estado de Sergipe e dos seus estratos no que diz respeito aos quantitativos de domić́lios pesquisados. As próximas quatro tabelas apresentam esses quantitativos e algumas considerações.

Na tabela 1 aparecem os dados relativos ao total do estado de Sergipe. Do total de domicílios sergipanos em ambos os anos, aproximadamente $99 \%$ responderam ao questionário qualitativo (relação B/A). No caso dos domicílios que responderam esse questionário e que apresentaram dados suficientes para possibilitar o calculo de seus balanços calóricos, em 2002, esse quantitativo foi de 413426 domicílios, representando $87,85 \%$ do total (relação C/A). Para 2009, esse percentual aumentou para $94,78 \%$. Esses números são importantes porque são a partir deles que se foi aplicado os critérios de separação entre domicílios pobres e domicílios não pobres, ou seja, são esses que compõe a amostra utilizada. 
Tabela 1. Quantitativos de domicílios para o estado de Sergipe

\begin{tabular}{lll}
\hline & $\mathbf{2 0 0 2}$ & $\mathbf{2 0 0 9}$ \\
\hline Número de domicílios (A) & 470606 & 565052 \\
Número de domicílios, que responderam o questionário & & \\
qualitativo (B) & 465808 & 560965 \\
B/A & $98.98 \%$ & $99.28 \%$ \\
Número de domicílios, que responderam o questionário & & \\
qualitativo e tiveram seus balanços calóricos calculados (C) & 413426 & 535553 \\
C/A & $87.85 \%$ & $94.78 \%$ \\
Número de domicílios satisfeitos com alimentação e cujo & & \\
balanço calórico é nulo ou positivo (D) & 44149 & 65723 \\
D/C & $10.68 \%$ & $12.27 \%$ \\
Número de domićlílos Insatisfeitos com alimentação e cujo & & \\
balanço calórico é negativo (E) & 92265 & 190826 \\
E/C & $22.32 \%$ & $35.63 \%$ \\
\hline
\end{tabular}

Fonte: Elaboração própria a partir dos dados da POF.

O quantitativo de domicílios ditos satisfeitos com a alimentação e que apresentaram balanço calórico nulo ou positivo (D), ou seja, os domicílios não pobres do estado de Sergipe representavam $10,68 \%$ do total de domicílios da amostra no ano de 2002 , e $12,27 \%$ no ano de 2009 . E quanto ao quantitativo dos domicílios considerados pobres, que são aqueles que apresentaram insatisfação com a alimentação e balanço calórico negativo, em 2002 representavam 22,32\% da amostra e passou a 35,63\% em 20095. Além do aumento de participação, o crescimento da quantidade de domicílios pobres foi muito maior do que o de domicílios não pobres, que pode ser visto comparando os quantitativos $\mathrm{D}$ e $\mathrm{E}$ da tabela.

Os quantitativos em relação ao estrato Capital estão apresentados na tabela 2. Pela relação $F / A$ vê-se a participação desse estrato no total de domicílios do estado, sendo $26,18 \%$ em 2002 e $28,89 \%$ em 2009. Quanto ao estabelecimento da amostra a ser analisada, ou seja, os domicílios que responderam ao questionário qualitativo e tiveram os balanços calóricos calculados, vê-se que em 2002 foram 103275 domicílios, crescendo para 151735 em 2009.

\footnotetext{
${ }^{5} \mathrm{O}$ somatório dos domicílios considerados pobres com os não pobres não necessariamente será igual a $100 \%$ dos domicílios. Isso porque há domicílios que aprese taram insatisfação com alimentação, mas balanço calórico positivo, ou balanço calórico positivo e que se classificaram como insatisfeitos, não classificando-os nem como pobres, e nem como não pobres.
} 
Tabela 2. Quantitativos de domicílios para o estrato Capital de Sergipe

\begin{tabular}{|c|c|c|}
\hline & 2002 & 2009 \\
\hline Número de domicílios (F) & 123195 & 163249 \\
\hline F/A & $26.18 \%$ & $28.89 \%$ \\
\hline $\begin{array}{l}\text { Número de domicílios, que responderam o questionário } \\
\text { qualitativo }(G)\end{array}$ & 120889 & 160642 \\
\hline $\mathrm{G} / \mathrm{F}$ & $98.13 \%$ & $98.40 \%$ \\
\hline $\begin{array}{l}\text { Número de domicílios, que responderam o questionário } \\
\text { qualitativo e tiveram seus balanços calóricos calculados }\end{array}$ & & \\
\hline (H) & 103275 & 151735 \\
\hline$H / F$ & $83.83 \%$ & $92.95 \%$ \\
\hline $\begin{array}{l}\text { Número de domicílios satisfeitos com alimentação e cujo } \\
\text { balanço calórico é nulo ou positivo (I) }\end{array}$ & 18082 & 22906 \\
\hline $\mathrm{l} / \mathrm{H}$ & $17.51 \%$ & $15.10 \%$ \\
\hline $\begin{array}{l}\text { Número de domicílios insatisfeitos com alimentação e } \\
\text { cujo balanço calórico é negativo }(\mathrm{J}) \\
\mathrm{J} / \mathrm{H}\end{array}$ & $\begin{array}{l}18446 \\
17.86 \%\end{array}$ & $\begin{array}{l}44747 \\
29.49 \%\end{array}$ \\
\hline
\end{tabular}

Fonte: Elaboração própria a partir dos dados das POFs

Desse total da amostra, os domicílios tidos como não pobres foram 18082 em 2002, representando $17,51 \%$ do total amostral, e 22906 , sendo $15,1 \%$ da amostra. No caso dos domicílios pobres, para 2002, foi bastante aproximado dos não pobres, sendo 18446, e representando $17,86 \%$. Porém no ano de 2009 , o número de domicílios pobres passou para 44747, e aumentou sua participação para $29,49 \%$ da amostra.

O estrato Urbano do estado, como se vê na tabela 3, é o que apresenta a maior participação no estado de Sergipe (relação K/A). Desse quantitativo, a amostra estabelecida, ou seja, os domicílios que responderam ao questionário qualitativo e tiveram seus balanços calóricos calculados (M), foi de 200823 em 2002 e de 267875 domicílios em 2009.

Para esse estrato, o quantitativo de domicílios não pobres para o ano de 2002 foi de 20265, representando 10\% do total da amostra, em 2009 foi de 27922, representando 10,4\%. Quanto aos domicílios pobres, no ano de 2002, a participação em relação ao total foi a maior entre os estratos, sendo de $24,38 \%$. Para 2009 essa participação foi de 34,75\%, que só foi menor do que para 0 estrato Rural, visto a seguir. 
Tabela 3. Quantitativos de domicílios para o estrato Urbano de Sergipe

\begin{tabular}{lll}
\hline & $\mathbf{2 0 0 2}$ & $\mathbf{2 0 0 9}$ \\
\hline Número de domicílios (K) & 228960 & 276093 \\
K/A & $48.65 \%$ & $48.86 \%$ \\
Número de domicílios que responderam o questionário & & \\
qualitativo (L) & 226469 & 274612 \\
L/K & $98.91 \%$ & $99.46 \%$ \\
Número de domicílios que responderam o questionário & & \\
qualitativo e tiveram seus balanços calóricos calculados & & \\
(M) & 200823 & 267875 \\
Q/K & $88.68 \%$ & $97.55 \%$ \\
Número de domicílios satisfeitos com alimentação e cujo & & \\
balanço calórico é nulo ou positivo (N) & 20265 & 27922 \\
N/M & $10.09 \%$ & $10.42 \%$ \\
Número de domicílios insatisfeitos com alimentação e & & \\
cujo balanço calórico é negativo (O) & 48957 & 93086 \\
O/M & $24.38 \%$ & $34.75 \%$ \\
\hline
\end{tabular}

Fonte: Elaboração própria a partir dos dados da POF.

Por fim, o estrato Rural do estado foi o único que passou por redução de quantidade de domicílios, como visto no item $\mathrm{P}$ da tabela 4, e que, em ambos os anos, $100 \%$ dos domicílios responderam ao questionário qualitativo.

Tabela 4. Quantitativos de domicílios para o estrato Rural de Sergipe

\begin{tabular}{lrr}
\hline & $\mathbf{2 0 0 2}$ & $\mathbf{2 0 0 9}$ \\
\hline Número de domicílios (P) & 118450 & 125711 \\
P/A & $25.2 \%$ & $22.2 \%$ \\
Número de domicílios que responderam o questionário & & \\
qualitativo (Q) & 118450 & 125711 \\
& & 100.0 \\
Q/P & $100.0 \%$ & $\%$ \\
Número de domicílios que responderam o questionário & & \\
qualitativo e tiveram seus balanços calóricos calculados & & \\
(R) & 109328 & 115942 \\
R/P & $92.3 \%$ & $92.2 \%$ \\
Número de domicílios satisfeitos com alimentação e cujo & & \\
balanço calórico é nulo ou positivo (S) & 5801.22 & 14896 \\
S/R & $5.3 \%$ & $12.8 \%$ \\
Número de domicílios insatisfeitos com alimentação e cujo & 24862.0 & \\
balanço calórico é negativo (T) & 9 & 52994 \\
T/R & $22.7 \%$ & $45.7 \%$ \\
\hline
\end{tabular}

Fonte: Elaboração própria a partir dos dados da POF.

Os domicílios que compuseram a amostra representavam aproximadamente $92 \%$ em ambos os anos. O número de domicílios que se enquadraram como não pobres nesse estrato foi o menor entre todos, representando 5,3\% em 2002. Para 2009, esse número representava $12,8 \%$. E 
quanto aos domicílios considerados pobres, para esse estrato, no ano de 2009, representaram $45,7 \%$ da amostra, sendo a maior participação entre todos os estratos. Para o ano de 2002, esse valor foi de $22,7 \%$.

O quadro um, a seguir, apresenta a nomenclatura dos quadros de despesas utilizados aqui, servindo como um meio de facilitação da leitura dos resultados.

Quadro 1. Discriminação dos quadros despesas usadas nesse trabalho

\begin{tabular}{|c|c|c|}
\hline $\begin{array}{l}\text { Qua } \\
\text { De }\end{array}$ & $\begin{array}{l}\text { dro de } \\
\text { spesa }\end{array}$ & Discriminação dos quadros de despesas \\
\hline \multirow{4}{*}{$\begin{array}{l}7 \text { dias } \\
90 \text { dias }\end{array}$} & & \\
\hline & quadro 7 & $\begin{array}{l}\text { aquisição de combustíveis domésticos e outros do } \\
\text { domicílio principal }\end{array}$ \\
\hline & quadro 8 & $\begin{array}{l}\text { conservação, manutenção e pequenos reparos } \\
\text { com habitação, jazigo e jardinagem }\end{array}$ \\
\hline & quadro 9 & $\begin{array}{l}\text { consertos e manutenção de móveis, aparelhos, } \\
\text { máquinas e utensílios de uso doméstico }\end{array}$ \\
\hline \multicolumn{2}{|c|}{12 meses } & \\
\hline & quadro 10 & $\begin{array}{l}\text { aluguel, impostos e outras taxas do domicilio } \\
\text { principal }\end{array}$ \\
\hline & quadro 11 & construção e reforma de habitação e jazigo \\
\hline \multirow{2}{*}{ Outras } & quadro 15 & $\begin{array}{l}\text { aquisição de aparelhos, máquinas e outras } \\
\text { utilidades de uso doméstico }\end{array}$ \\
\hline & quadro 16 & $\begin{array}{l}\text { aquisição de ferramentas, animais domésticos, } \\
\text { equipamentos musicais e de acampamento }\end{array}$ \\
\hline Saúde & $\begin{array}{l}\text { quadro } 17 \\
\text { quadro } 42\end{array}$ & $\begin{array}{l}\text { aquisição de móveis } \\
\text { despesas com serviços de saúde }\end{array}$ \\
\hline
\end{tabular}

Fonte: Elaboração própria a partir dos dados das POFs.

\subsection{Estrato Capital}

De acordo com a análise dos preços relativos foram selecionados, para 0 estrato Capital, os itens de despesas apresentados na tabela 5, em que aparecem também os preços relativos previamente calculados para os dois anos de análise e suas variações, tanto para domicílios pobres quanto para não pobres. Para esses grupos de despesas, como pode-se notar na tabela, as variações dos preços relativos são mais prejudiciais aos domicílios pobres.

Para os domicílios que realizaram gastos com os itens do quadro $7 \mathrm{da}$ tabela de despesas de 90 dias que representa gastos com aquisição de combustíveis domésticos e outros do domicílio principal, o preço relativo para os domicílios pobres reduziu-se em $29 \%$, mas não reduziu tanto quanto reduziu para os domicílios não pobres, $55 \%$. Mesmo caso ocorreu para os domicílios 
com despesas no quadro 10 da tabela de despesas de 12 meses, ou seja, gastos com aluguel, impostos e outras taxas do domicílio principal. Para o caso do quadro 9 (consertos e manutenção de móveis, aparelhos, máquinas e utensílios de uso doméstico) e da tabela de despesas com veículos, os preços reduziram para os domicílios não pobres e aumentaram para os pobres. E para os restantes, houve aumento para ambos os grupos de domicílios, mas os domicílios pobres passaram por um aumento maior.

\begin{tabular}{|c|c|c|c|c|c|c|}
\hline \multirow{2}{*}{$\begin{array}{l}\text { Item de } \\
\text { despesa }\end{array}$} & \multicolumn{3}{|c|}{ P. Relativo - Não pobres } & \multicolumn{3}{|c|}{ P. Relativo - Pobres } \\
\hline & 2002 & 2009 & Variação & 2002 & 2009 & Variação \\
\hline \multicolumn{7}{|l|}{90 dias } \\
\hline quadro 7 & 11.66 & 5.25 & $-55 \%$ & 8.46 & 5.96 & $-29 \%$ \\
\hline quadro 8 & 21.96 & 23.53 & $7 \%$ & 13.51 & 19.25 & $43 \%$ \\
\hline quadro 9 & 10.04 & 6.56 & $-35 \%$ & 6.91 & 8.46 & $23 \%$ \\
\hline \multicolumn{7}{|l|}{12 meses } \\
\hline quadro 10 & 65.92 & 31.93 & $-52 \%$ & 41.98 & 29.75 & $-29 \%$ \\
\hline \multicolumn{7}{|l|}{ Outras } \\
\hline quadro 16 & 1.86 & 2.72 & $46 \%$ & 0.73 & 2.65 & $262 \%$ \\
\hline Veículos & 247.33 & 219.76 & $-11 \%$ & 30.89 & 88.45 & $186 \%$ \\
\hline
\end{tabular}

Fonte: Elaboração própria a partir dos dados da POF.

A próxima tabela (tabela 6 ) mostra os preços relativos calculados para os domicílios que realizaram despesas simultaneamente com alimentação e com os itens de despesas. Ou seja, por exemplo, na primeira linha de dados, 8,38 representa o preço relativo à alimentação pago em 2002 pelos domicílios pobres que realizaram despesas com alimentação e com itens do quadro 7 da tabela de despesas de 90 dias; 6,28 representa o mesmo preço, só que pago em 2009; e $-25 \%$ representa a variação entre esses dois preços.

Tabela 6. Preços Relativos para os gastos simultâneos com alimentação Estrato Capital

\begin{tabular}{cllllll}
\hline Item de & \multicolumn{5}{c}{ P. Relativo - Não Pobres } & P. Relativo - Pobres \\
despesa & $\mathbf{2 0 0 2}$ & $\mathbf{2 0 0 9}$ & Variação & $\mathbf{2 0 0 2}$ & $\mathbf{2 0 0 9}$ & Variação \\
\hline 90 dias & & & & & & \\
$\quad$ quadro 7 & 11.41 & 6.60 & $-42 \%$ & 8.38 & 6.28 & $-25 \%$ \\
$\quad$ quadro 8 & 20.01 & 25.03 & $25 \%$ & 15.16 & 18.70 & $23 \%$ \\
$\quad$ quadro 9 & 10.57 & 5.60 & $-47 \%$ & 8.11 & 7.75 & $-4 \%$ \\
$\begin{array}{c}12 \text { meses } \\
\text { quadro 10 }\end{array}$ & 64.25 & 31.16 & $-51 \%$ & 42.79 & 30.78 & $-28 \%$ \\
$\begin{array}{c}\text { Outras } \\
\quad \text { quadro 16 }\end{array}$ & 1.90 & 2.84 & $49 \%$ & 0.64 & 2.01 & $216 \%$ \\
Veículos & 297.10 & 294.65 & $-1 \%$ & 41.89 & 61.27 & $46 \%$ \\
\hline
\end{tabular}

Fonte: Elaboração própria a partir dos dados da POF.

Nessa segunda etapa da análise, percebe-se que, para o quadro 7 (gastos com aquisição de combustíveis domésticos e outros do domicílio principal) os preços relativos a alimentação reduziram para ambos os grupos de 
domicílios, porém ficou mais barato para os domicílios não pobres, sendo uma situação mais prejudicial para os domicílios pobres. Mesmo ocorreu para os quadro 9 e 10, que representam consertos e manutenção de móveis, aparelhos, máquinas e utensílios de uso doméstico e os gastos com aluguel, impostos e outras taxas do domicílio principal. O quadro 16 (aquisição de ferramentas, animais domésticos, equipamentos musicais e de acampamento) apresentou elevação de preços para ambos os grupos de domicílios, mas em maior percentual para os pobres. E as despesas com veículos ficaram mais caras $46 \%$ para os pobres, e reduziram em $1 \%$ para os não pobres.

Assim, quando esses resultados são comparados com a tabela 5, somente não se confirma o quadro 8 , despesas com conservação, manutenção e pequenos reparos com habitação, jazigo e jardinagem, como sendo indicador de multa, mas os restantes, de acordo com as duas fases do teste, indicam fortemente que os domicílios pobres sofrem com a atuação da multa da pobreza nesses tipos de gastos.

\subsection{Estrato Rural}

Conforme tabela 7, entre todos os itens de despesas selecionados como tendo variado de maneira desfavorável aos pobres, somente um não indicou aumento de preço. Esse foi o quadro 42, que são as despesas com serviços de saúde que apresentou redução de $85 \%$ nos preços relativos, mas não reduziu mais do que os preços relativos dos domicílios não pobres (95\%). Todos os dados relacionados a saúde coletados indicaram redução de preços pagos, o que tem relação com o texto de Diniz et al (2007), que fala sobre a influência da implantação do SUS sobre os gastos das famílias com saúde no Brasil.

Tabela 7. Preços Relativos para gastos diretos - Estrato Rural

\begin{tabular}{cllllll}
\hline Item de & \multicolumn{2}{c}{ P. Relativo - Não pobres } & \multicolumn{3}{c}{ P. Relativo - Pobres } \\
despesa & $\mathbf{2 0 0 2}$ & $\mathbf{2 0 0 9}$ & Variação & $\mathbf{2 0 0 2}$ & $\mathbf{2 0 0 9}$ & Variação \\
\hline 90 dias & & & & & & \\
quadro 7 & 8.39 & 5.62 & $-33 \%$ & 5.41 & 7.08 & $31 \%$ \\
$\quad$ quadro 8 & 9.80 & 12.00 & $22 \%$ & 4.49 & 8.08 & $80 \%$ \\
$\begin{array}{c}\text { Outras } \\
\quad \text { quadro 15 }\end{array}$ & 9.11 & 7.50 & $-18 \%$ & 2.98 & 8.87 & $197 \%$ \\
$\quad$ quadro 16 & 1.06 & 0.87 & $-18 \%$ & 0.84 & 1.20 & $43 \%$ \\
$\begin{array}{c}\text { Saúde } \\
\quad \text { quadro 42 }\end{array}$ & 225.95 & 12.04 & $-95 \%$ & 91.73 & 13.76 & $-85 \%$ \\
Veículos & 39.75 & 170.16 & $328 \%$ & 1.94 & 56.10 & $2785 \%$ \\
\hline
\end{tabular}

Fonte: Elaboração própria a partir dos dados da POF.

O grande diferencial do estrato rural é quando se observa a segunda etapa da análise (tabela 8), relacionada aos preços relativos dos domicílios com despesas simultâneas com alimentação e os itens de despesas indicados na tabela, todos os indícios de multa da pobreza são confirmados. Em todos os casos a variação dos preços relativos foi mais prejudicial para os domicílios 
pobres, até mesmo quando se reduziu o preço relativo do quadro 42 das despesas com serviços de saúde, em razão de ter reduzido mais para os domicílios não pobres (96\%).

Tabela 8. Preços Relativos para os gastos simultâneos com alimentação - Estrato Rural

\begin{tabular}{ccccccc}
\hline $\begin{array}{c}\text { Item de } \\
\text { despesa }\end{array}$ & $\mathbf{2}$ & Não Pobres & \multicolumn{3}{c}{ Pobres } \\
\hline 90 dias & $\mathbf{2 0 0 9}$ & Variação & $\mathbf{2 0 0 2}$ & $\mathbf{2 0 0 9}$ & Variação \\
$\quad$ quadro 7 & 12.97 & 5.61 & $-57 \%$ & 5.50 & 6.58 & $20 \%$ \\
$\quad$ quadro 8 & 10.46 & 8.07 & $-23 \%$ & 8.07 & 9.57 & $19 \%$ \\
$\begin{array}{c}\text { Outras } \\
\quad \text { quadro 15 }\end{array}$ & 8.67 & 8.17 & $-6 \%$ & 5.36 & 9.05 & $69 \%$ \\
$\quad$ quadro 16 & 0.61 & 0.62 & $3 \%$ & 0.87 & 1.28 & $47 \%$ \\
$\begin{array}{c}\text { Saúde } \\
\quad \text { quadro 42 }\end{array}$ & 370.42 & 14.93 & $-96 \%$ & 68.40 & 11.87 & $-83 \%$ \\
Veículos & 99.79 & 203.96 & $104 \%$ & 12.93 & 51.30 & $297 \%$ \\
\hline
\end{tabular}

Fonte: Elaboração própria a partir dos dados da POF.

Assim, fica claro que para esses grupos de despesas, os domicílios do estrato rural que realizaram gastos com eles sofreram com a atuação da multa da pobreza segundo o conceito de Prahalad (2005).

\subsection{Estrato Urbano}

Por fim, o estrato Urbano seguiu o mesmo padrão entre os outros estratos no que diz respeito às variações de preços serem positivas para os domicílios pobres. Para o estrato Urbano do estado de Sergipe, de acordo com a primeira fase do teste da multa da pobreza segundo Prahalad (2005), foram selecionados os grupos de despesas que constam na tabela a seguir (tabela 9). Pelas variações dos preços relativos percebe-se que, para todos esses grupos de despesas, ou melhor, para os domicílios que realizaram gastos nos grupos de despesas que constam na tabela, os domicílios pobres foram mais prejudicados com a dinâmica da variação de preços no passar dos anos. Já com uma olhada geral se percebe que para os pobres houve predominância de aumento de preços, sendo exceção somente o quadro 11 das despesas de 12 meses (construção e reforma de habitação e jazigo), com redução de 5\%, e que para os domicílios não pobres predominou as reduções de preços, com exceção do quadro 17 (aquisição de móveis) e das despesas com veículos, que, entre todos os estratos, só se reduziu para os domicílios não pobres do estrato capital. 
Tabela 9. Preços Relativos para gastos diretos - Estrato Urbano

\begin{tabular}{|c|c|c|c|c|c|c|}
\hline \multirow{2}{*}{$\begin{array}{l}\text { Item de } \\
\text { despesa }\end{array}$} & \multicolumn{3}{|c|}{ P. Relativo - Não pobres } & \multicolumn{3}{|c|}{ P. Relativo - Pobres } \\
\hline & 2002 & 2009 & Variação & 2002 & 2009 & Variação \\
\hline 7 dias & 1.34 & 1.15 & $-14 \%$ & 0.60 & 0.95 & $59 \%$ \\
\hline \multicolumn{7}{|c|}{90 dias } \\
\hline quadro 7 & 9.24 & 6.95 & $-25 \%$ & 6.32 & 6.50 & $3 \%$ \\
\hline quadro 9 & 11.27 & 7.13 & $-37 \%$ & 6.77 & 7.51 & $11 \%$ \\
\hline \multicolumn{7}{|c|}{12 meses } \\
\hline quadro 10 & 56.06 & 20.48 & $-63 \%$ & 26.18 & 26.57 & $1 \%$ \\
\hline quadro 11 & 16.44 & 7.22 & $-56 \%$ & 6.28 & 5.99 & $-5 \%$ \\
\hline \multicolumn{7}{|c|}{ Outras } \\
\hline quadro 15 & 9.07 & 8.92 & $-2 \%$ & 5.10 & 6.91 & $35 \%$ \\
\hline quadro 17 & 10.37 & 16.53 & $59 \%$ & 5.45 & 10.37 & $90 \%$ \\
\hline Veículos & 70.39 & 96.31 & $37 \%$ & 20.41 & 35.93 & $76 \%$ \\
\hline
\end{tabular}

Fonte: Elaboração própria a partir dos dados da POF.

Sendo claro que, quando há aumento de preços para os pobres e redução para os não pobres, isso indica atuação de multa da pobreza, é preciso somente explicar as exceções. A multa se configura no caso da redução de $5 \%$ dos preços pagos pelos domicílios pobres nas despesas com construção e reforma de habitação e jazigo a medida que observa-se que os domicílios não pobres tiveram seus preços reduzidos muito mais, em $56 \%$. E no caso em que houve aumento de preços para os domicílios não pobres, houve aumento maior para os domicílios pobres, evidenciando a sua pior situação.

Quando passamos a observar a segunda fase da análise, observando os preços relativos também a alimentação, dos domicílios com despesas com alimentação e com os itens em questão, na tabela 10, percebe-se a mesma situação que o estrato capital apresentou: somente um item de despesa não se comprovou como multa da pobreza.

Tabela 10. Preços Relativos para os gastos simultâneos com alimentação - Estrato Urbano

\begin{tabular}{|c|c|c|c|c|c|c|}
\hline \multirow{2}{*}{$\begin{array}{l}\text { Item de } \\
\text { despesa }\end{array}$} & \multicolumn{3}{|c|}{ P. Relativo - Não Pobres } & \multicolumn{3}{|c|}{ P. Relativo - Pobres } \\
\hline & 2002 & 2009 & Variação & 2002 & 2009 & Variação \\
\hline 7 dias & 0.93 & 1.42 & $52 \%$ & 0.77 & 1.21 & $57 \%$ \\
\hline \multicolumn{7}{|l|}{90 dias } \\
\hline quadro 7 & 9.46 & 7.40 & $-22 \%$ & 7.19 & 7.31 & $2 \%$ \\
\hline quadro 9 & 13.59 & 7.81 & $-43 \%$ & 6.31 & 9.02 & $43 \%$ \\
\hline \multicolumn{7}{|c|}{12 meses } \\
\hline quadro 10 & 61.87 & 22.61 & $-63 \%$ & 29.34 & 36.22 & $23 \%$ \\
\hline quadro 11 & 8.78 & 8.15 & $-7 \%$ & 5.30 & 8.28 & $56 \%$ \\
\hline \multicolumn{7}{|c|}{ Outras } \\
\hline quadro 15 & 10.27 & 9.48 & $-8 \%$ & 5.90 & 7.92 & $34 \%$ \\
\hline quadro 17 & 9.77 & 19.18 & $96 \%$ & 6.34 & 11.70 & $84 \%$ \\
\hline Veículos & 86.38 & 98.71 & $14 \%$ & 22.51 & 48.69 & $116 \%$ \\
\hline
\end{tabular}

Fonte: Elaboração própria a partir dos dados das POFs 
Nessa etapa, todos os preços relativos pagos pelos domicílios pobres sofreram aumento. E quando comparados com os preços pagos pelos não pobres, vê-se que sempre a variação foi maior para os domicílios pobres. A única exceção é para a aquisição de móveis (quadro 17), onde o aumento de preços foi de $84 \%$ para os domicílios pobres e de $96 \%$ para os não pobres. Sendo assim, fica claro que os domicílios pobres do estrato urbano que realizaram despesas dos tipos encontrados na tabela, excluído o quadro 17, sofreram com a atuação da multa da pobreza.

\section{ANÁLISE DOS RESULTADOS}

Apresenta-se aqui o resultado da variável teste, baseado na participação que as despesas de certo item tem em relação a renda do domicílios. Ou seja, o quanto a despesa daquele item representam na renda domiciliar. Indica-se situação prejudicial para os domicílios pobres quando essa participação aumenta mais para esses domicílios do que para os não pobres.

Sendo assim, as nas tabelas 11, 12 e 13, as colunas indicada por "Relação" representam a relação entre a participação da despesa do item na renda do domicílio e a participação da despesa com alimentação na renda do mesmo domicílio, conforme mencionado na metodologia deste trabalho.

Em razões de melhor visualização, as tabelas apresentam somente os quadros e grupos de despesas onde foi encontrado indícios de multa da pobreza inicialmente, sendo então a coluna Variável Hipótese composta toda pelo índice 1.

O estrato Capital é representado na tabela abaixo:

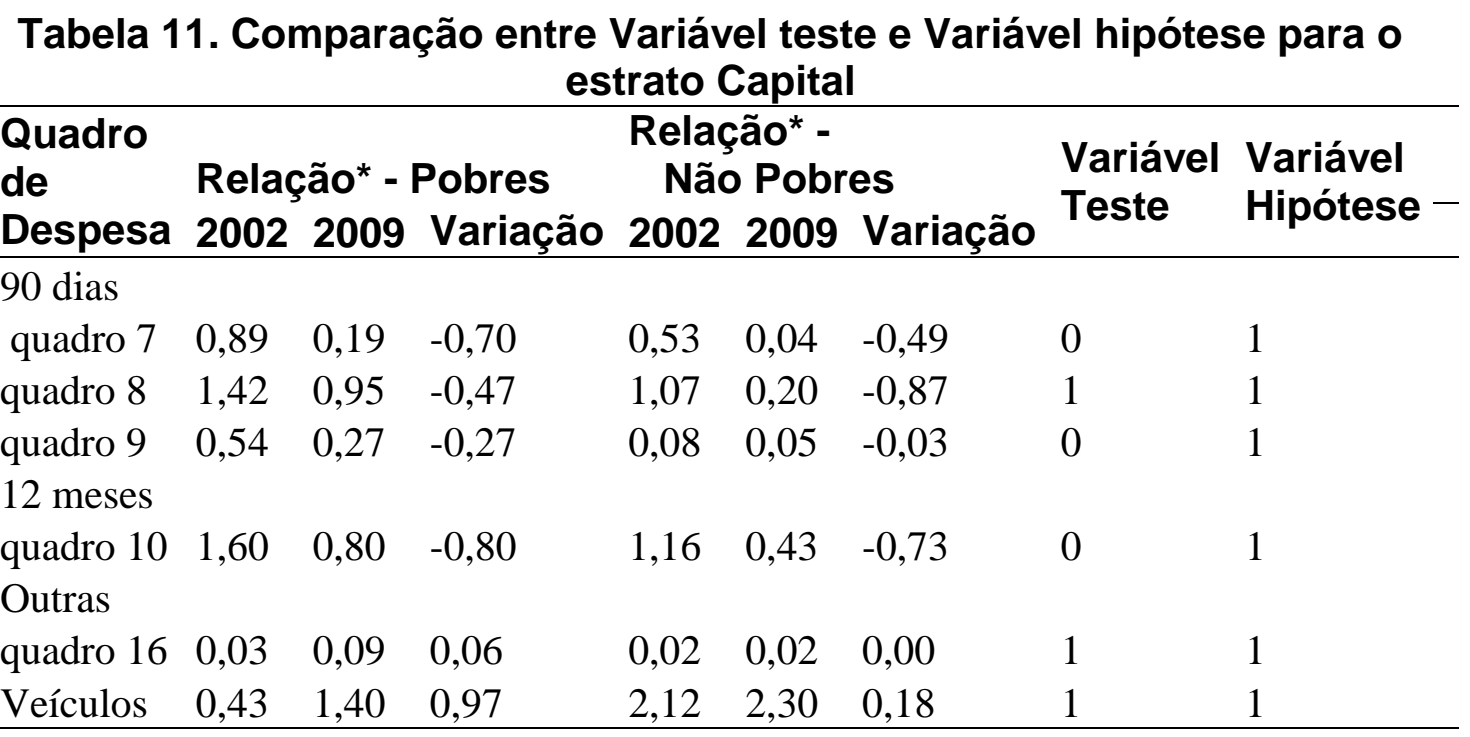

Fonte: Elaboração própria a partir dos dados das POFs.

* Relação: (Desp Item/Renda)/(Desp Alimentação/Renda)

Nela percebe-se que seis grupos de despesas foram indicados como multa da pobreza segundo a análise de preços relativos. Porém, ao se buscar 
confirmação com o teste da participação da despesa na renda, relacionada a alimentação, vê-se que três desses grupos indicam multa também. Sendo assim, para esses três grupos de despesas a multa da pobreza é reafirmada e confirmada pelo teste.

Dessa forma, as despesas com conservação, manutenção e pequenos reparos com habitação, jazigo e jardinagem (quadro 8), as despesas com aquisição de ferramentas, animais domésticos, equipamentos musicais e de acampamento (quadro 16), e as despesas com veículos são os grupos de despesas, para o estrato capital, onde os pobres são prejudicados pela incidência da multa da pobreza.

Em relação ao estrato Rural, este apresentou também seis grupos de despesas com indícios de multa da pobreza. Com a comparação com a coluna da variável teste na tabela 12, percebe-se que, agora, houve quatro grupos onde se confirmaram a multa. Eles foram os mesmos três do estrato Capital (quadros 8 e 16 e despesas com veículos) mais o quadro 15, representando a aquisição de aparelhos, máquinas e outras utilidades domesticas.

Tabela 12. Comparação entre Variável teste e Variável hipótese para o estrato Rural

\begin{tabular}{|c|c|c|c|c|c|c|c|c|}
\hline \multirow{2}{*}{$\begin{array}{l}\text { Quadro } \\
\text { de } \\
\text { Despesa }\end{array}$} & \multicolumn{3}{|c|}{ Relação* - Pobres } & \multicolumn{3}{|c|}{$\begin{array}{l}\text { Relação* } \\
\text { Não Pobres }\end{array}$} & \multirow{2}{*}{$\begin{array}{l}\text { Variável } \\
\text { Teste }\end{array}$} & \multirow{2}{*}{$\begin{array}{l}\text { Variável } \\
\text { Hipótese }\end{array}$} \\
\hline & 2002 & 2009 & Variação & 2002 & 2009 & Variação & & \\
\hline \multicolumn{9}{|l|}{90 dias } \\
\hline quadro 7 & 0,34 & 0,13 & $-0,21$ & 0,13 & 0,05 & $-0,08$ & 0 & 1 \\
\hline quadro 8 & 0,33 & 0,47 & 0,14 & 0,21 & 0,13 & $-0,08$ & 1 & 1 \\
\hline \multicolumn{9}{|c|}{ Outras } \\
\hline quadro15 & 0,13 & 0,21 & 0,08 & 0,09 & 0,07 & $-0,02$ & 1 & 1 \\
\hline quadro16 & 0,01 & 0,02 & 0,01 & 0,01 & 0,02 & 0,01 & 1 & 1 \\
\hline \multicolumn{9}{|c|}{ Saúde } \\
\hline quadro42 & 0,96 & 0,39 & $-0,57$ & 0,33 & 0,19 & $-0,14$ & 0 & 1 \\
\hline Veículos & 0,05 & 2,27 & 2,22 & 0,26 & 1,94 & 1,68 & 1 & 1 \\
\hline
\end{tabular}

Fonte: Elaboração própria a partir dos dados das POFs.

* Relação: (Desp Item/Renda)/(Desp Alimentação/Renda)

O estrato Urbano por sua vez apresentou a maior quantidade de grupos indicando multa da pobreza: os oito grupos indicados na tabela abaixo. Porém, ao se realizar a análise baseada na variável teste, de acordo com a tabela 13, somente dois grupos se confirmam como ocorrência de multa da pobreza, que é a despesas de 7 dias e despesas com alugueis, impostos e outras taxas de domicílio (quadro 10). 
Tabela 13. Comparação entre Variável teste e Variável hipótese para o estrato Urbano

\begin{tabular}{|c|c|c|c|c|c|c|c|c|}
\hline $\begin{array}{l}\text { Quadro } \\
\text { de } \\
\text { Despesa }\end{array}$ & $\begin{array}{l}\text { Rela } \\
2002\end{array}$ & $\begin{array}{l}\text { ão* - } \\
2009\end{array}$ & $\begin{array}{l}\text { Pobres } \\
\text { Variação }\end{array}$ & $\begin{array}{l}\text { Relac } \\
\text { Não } \\
2002\end{array}$ & $\begin{array}{l}\text { ãa }{ }^{*}- \\
\text { Pobr } \\
2009\end{array}$ & es & $\begin{array}{l}\text { Variável } \\
\text { Teste }\end{array}$ & $\begin{array}{l}\text { Variável } \\
\text { Hipótese }\end{array}$ \\
\hline $\begin{array}{l}7 \text { dias } \\
90 \text { dias }\end{array}$ & 0,06 & 0,35 & 0,29 & 0,25 & 0,14 & $-0,11$ & 1 & 1 \\
\hline quadro 7 & 0,72 & 0,16 & $-0,56$ & 0,29 & 0,06 & $-0,23$ & 0 & 1 \\
\hline $\begin{array}{l}\text { quadro } 9 \\
12 \text { meses }\end{array}$ & 0,27 & 0,18 & $-0,09$ & 0,04 & 0,06 & 0,02 & 0 & 1 \\
\hline quadro 10 & 0,99 & 0,69 & $-0,30$ & 0,54 & 0,19 & $-0,35$ & 1 & 1 \\
\hline $\begin{array}{l}\text { quadro } 11 \\
\text { Outras }\end{array}$ & 0,56 & 0,46 & $-0,10$ & 0,17 & 0,23 & 0,06 & 0 & 1 \\
\hline quadro 15 & 0,35 & 0,28 & $-0,07$ & 0,18 & 0,15 & $-0,04$ & 0 & 1 \\
\hline quadro 17 & 0,30 & 0,27 & $-0,03$ & 0,14 & 0,19 & 0,05 & 0 & 1 \\
\hline Veículos & 0,73 & 0,83 & 0,10 & 0,54 & 0,66 & 0,11 & 0 & 1 \\
\hline
\end{tabular}

Fonte: Elaboração própria a partir dos dados das POFs.

* Relação: (Desp Item/Renda)/(Desp Alimentação/Renda)

\section{CONSIDERAÇÕES FINAIS}

O presente trabalho tratou da pobreza no estado de Sergipe a partir da ótica da multa da pobreza, uma das diversas abordagens sobre o tema. $O$ objetivo principal do trabalho foi constatar, para Sergipe, a existência desse fenômeno, que indica que os domicílios pobres enfrentariam maior custo na realização das despesas do que os não pobres.

Â luz do conceito formulado por Prahalad (2005), indicou-se que a relação entre despesas com alimentação com outras despesas em geral foi prejudicial para os domicílios pobres.

A partir dos cálculos realizados e dos resultados obtidos pode-se afirmar então que a existência da multa da pobreza para o estado de Sergipe foi confirmada. Mais do que isso, que a incidência dessa multa é diferente para cada estrato. $O$ estrato rural foi o que apresentou a maior incidência de multa da pobreza em relação a variável teste, no sentido de Prahalad (2005), ou seja, quatro grupos de despesas. Os aumentos de preços nos grupos de despesas relacionadas à conservação e manutenção de habitação, jazigo e jardinagem (quadro 8), aquisição de aparelhos e máquinas, ferramentas, animais domésticos e equipamentos (quadros 15 e 16), e despesas com veículos, tendem a piorar a situação dos domicílios pobres desse estrato.

Os domicílios pobres do estrato rural são os únicos que sofrem pela multa da pobreza nos gastos realizados a habitação e a aquisição de aparelhos domésticos (quadros 8 e 15).

Portanto, a multa da pobreza foi detectada para diferentes estratos do estado de Sergipe e diferentes grupos de despesas. Isto aconteceu quando observados os grupos de alimentos e também quando considerado o grupo de despesas com alimentação como um só e se comparou com ele outros grupos de despesas. Os estratos regionais sergipanos, diferenciados entre capital, rural 
e urbano, apresentam diferentes grupos de alimentação em que se constatou multa da pobreza, porém, há algumas semelhanças entre eles. No critério comparativo do grupo de despesa com alimentação com outros grupos, o estrato urbano se diferenciou, apesar de ter sido no estrato rural onde um número maior de multas desse tipo foi constatado. Assim, resulta do que foi dito, que mudanças nos preços de diferentes grupos de alimentos afetam de forma comum, para alguns grupos de alimentos, a todos os estratos sergipanos, mas afeta mais 0 estrato urbano. Mudanças nos preços de outros grupos de despesas, comparativamente aos preços dos alimentos, por sua vez, afetam de forma diferenciada o estrato urbano, embora afete mais o estrato rural.

Logo se verifica a existência da multa da pobreza no Estado de Sergipe, para os três estratos analisados. Outras metodologias podem ser tratadas com o objetivo de indicar a multa da pobreza, assim como, outros gastos podem ser considerados "catastróficos" sob o modelo utilizado por Prahalad (2005) para verificar a incidência de tal fenômeno.

\section{REFERÊNCIAS BIBLIOGRÁFICAS}

CAPLOVITZ, D. "The Poor Pay More: Consumer Practices of Low Income Families". Free Press of Glencoe: Toronto, Ontario, 1963.

HAMMOND, A. L, KRAMER, W. J, KATZ, R. S, TRAN, J. T, WALKER, C. "The Next Four Billion: Market Size and Business Strategy at the Base of the Pyramid". World Resources Institute and the International Finance Corporation: Washington, DC, 2007. Disponível em http://pdf.wri.org/n4b_fulltext_hi.pdf.

IBGE. Pesquisa de Orçamentos Familiares. Rio de Janeiro, 2002-2003. CDROM.

IBGE. Pesquisa de Orçamentos Familiares. Rio de Janeiro, 2008-2009, CDROM.

KUNREUTHER, H. "Why the poor pay more for food: theoretical and empirical evidence". The Journal of Business 46(3): 368-383, 1973.

MENDOZA, R. U. "Why do the poor pay more? Exploring the poverty penalty concept". Journal of International Development. 23 ed, 1-28, 2011.

PRAHALAD, C. K. "Fortune at the Bottom of the Pyramid: Eradicating Poverty through Profits". Wharton School Publishing: Philadelphia, Penn, 2005. 